\title{
FAKTOR DOMINAN YANG MEMPENGARUHI KEJADIAN DERMATITIS KONTAK DAN DAMPAKNYA TERHADAP KUALITAS HIDUP PADA PETANI RUMPUT LAUT DI DUSUN PUNTONDO TAKALAR
}

\section{DOMINANT FACTORS AFFECT CONTACT DERMATITIS CONTACT AND ITS IMPACT TOWARDS SEAWEED FARMERS LIFE QUALITY IN PUNTONDO VILLAGE TAKALAR}

\author{
Atjo Wahyu, A.Ummu Salmah, A.Rifkah Fauziah A, Mayang Amalia Angradipta, Syamsiar \\ Russeng
}

Fakultas Kesehatan Masyarakat Universitas Hasanuddin

\begin{abstract}
ABSTRAK
Negara Republik Indonesia Terkenal sebagai archipelagos of State oleh karena memiliki banyak pulau baik yang kecil maupun yang besar. Kondisi ini menyebabkan banyak penduduk yang bermukim dan mencari hidup dan kehidupannya (penghidupan) di sekitar pesisir kepulauan. Tujuan Penelitian ini adalah untuk menganalisis variabel yang paling dominan dalam mempengaruhi kejadian dermatitis kontak dan dampaknya pada kualitas hidup pada petani rumput laut. Variabel bebas dalam penelitian ini sebanyak 8 yaitu umur, lama kerja, masa kerja, pendidikan, pengetahuan ,sikap, tindakan, penggunaan alat pelindung diri, selanjutnya variabel dermatitis kontak dianalisis dampaknya terhadap variabel kualitas hidup. Jenis Penelitian menggunakan pendekatan cross sectional study, dengan besar sampel sebanyak 128 petani rumput laut. Hasi uji regresi logistic menemukan bahwa faktor yang paling dominan yang mempengaruhi kejadian dermatitis kontak adalah Penggunaan alat pelindung diri $(p=0,008)$ dan selanjutnya dengan menggunakan Uji Man Whitney didapatkan bahwa kualitas hidup bagi petani rumput laut yang menderita dermatitis kontak lebih rendah dibandingkan dengan petani rumput laut yang tidak menderita dermatitis kontak.
\end{abstract}

Keyword: Dominant factors, Quality of Life, Agent biology, Dermatitis Contact

\begin{abstract}
The Republic of Indonesia is famous as the archipelagos of State since it has a lot of islands both small and large. This condition causes a lot of people that live and look for life and living (livelihood) around the coastal islands. This situation occurs in seaweed farmers Takalar. The aim of this study was to analyze the most dominant variable in influencing the incidence of contact dermatitis and its impact on quality of life in seaweed farmers. The independent variables in this study were 8 such as age, length of employment, length of employment, education, knowledge, attitudes, action, use of personal protective equipment, then contact dermatitis variables analyzed its impact on quality of life variables. Types of research used cross sectional study, with a sample size of 128 seaweed farmers. Result from logistic regression found that the most dominant factor affecting the incidence of contact dermatitis is the use of personal protective equipment $(p=0.008)$ and subsequently by using the Test of Man Whitney was found that the quality of life for seaweed farmers suffering from contact dermatitis was lower than the farmer grass sea that do not suffer from contact dermatitis.
\end{abstract}

Keyword: Dominant factors, Quality of Life, Agent biology, Contact Dermatitis 


\section{PENDAHULUAN}

Dermatitis kontak adalah respon dari kulit dalam bentuk peradangan yang dapat bersifat akut maupun kronik, karena paparan dari bahan iritan eksternal yang mengenai kulit (Lestari dan Utomo, 2007). Peradangan kulitt ini disertai dengan adanya spongiosis/edema interseluler (Harahap, 2013).

Kejadian dermatitis dipengaruhi oleh faktor langsung (ukuran molekul, daya larut dan konsentrasi) dan tidak langsung (suhu, kelembaban, masa kerja, usia, jenis kelamin, ras, riwayat penyakit sebelumnya, personal hygiene dan penggunaan APD) dan lama kontak (Suryani, 2011). Berbagai aspek dapat menjadi pemicu kejadian dermatitis baik faktor internal ataupun eksternal.

Dermatitis kontak akibat kerja merupakan salah satu penyakit akibat kerja yang paling banyak dijumpai, Kelainan kulit ini dapat ditemukan sekitar 85\% sampai 98\% dari seluruh penyakit kulit akibat kerja. Insiden dermatitis kontak akibat kerja diperkirakan sebanyak 0,5 sampai 0,7 kasus per 1000 pekerja per tahun. Penyakit kulit diperkirakan menempati $9 \%$ sampai $34 \%$ dari penyakit yang berhubungan dengan pekerjaan (Cahyawati, 2011).

Biro Statistik Amerika Serikat (1988) menyatakan bahwa penyakit kulit menduduki sekitar 24\% dari seluruh PAK yang dilaporkan. National Institute of Occupation Safety Hazards (NIOSH) dalam survei tahunan (1975) memperkirakan angka kejadian dermatitis akibat kerja yang sebenarnya adalah 20-50 kali lebih tinggi dari kasus yang telah dilaporkan (Cahyawati, 2011).

Dermatitis kontak akibat kerja merupakan penyakit dengan prevalensi kejadian tertinggi pertama di beberapa negara, angka insidennya mencapai 0,5-1,9 kasus per 1000 jam kerja/tahun (Diepgen, 1999). Data dari United Stases Bureau of Labor Statistict Annual Survey of Occupational Injuries and Illnesses pada tahun 1988, didapatkan 24\% kasus penyakit akibat kerja adalah kelainan atau penyakit kulit (Suryani, 2011).

Prevalensi dermatitis di Indonesia sendiri sangat bervariasi. Pada pertemuan Dokter Spesialis Kulit tahun 2009 dinyatakan Sekitar 90\% penyakit kulit akibat kerja merupakan dermatitis kontak, baik iritan maupun alergik (Hamzah dan Wintoko, 2014). Penyakit kulit akibat kerja yang merupakan dermatitis kontak sebesar 92,5\%, sekitar 5,4\% karena infeksi kulit dan 2,1\% penyakit kulit karena sebab lain. Pada studi epidemiologi, Indonesia memperlihatkan bahwa 97\% dari 389 kasus adalah dermatitis kontak, dimana $66,3 \%$ diantaranya adalah dermatitis kontak iritan dan 33,7\% adalah dermatitis kontak alergi (Mustikawati dkk, 2012).

Dermatitis merupakan penyakit kulit yang mempunyai efek psikologis pada penderitanya dan dapat menyebabkan gangguan yang cukup signifikan terhadap kualitas hidup penderita seringkali merasa memperoleh stigma yang sangat mengerikan, mempunyai citra diri yang buruk serta merasa rendah diri (Graham dan Burns, 2011).

Data Riset Kesehatan Dasar menyebutkan bahwa prevalensi penyakit kulit di Indonesia sebesar 6,8\%, di Sulawesi Selatan sebesar 53,2\%. Data Dinas Kesehatan Kabupaten Takalar tahun 2013 mencantumkan bahwa penyakit dermatitis adalah penyakit yang berada di urutan kedua dari 10 Penyakit tertinggi di Kabupaten Takalar, jumlahnya sebanyak 28.530 kasus, dengan prevalensi 0,11\% (Depkes, 2011 dan Dinkes Takalar, 2014.

Data PKM Puskesmas Pattopakang yang merupakan satu-satunya akses pelayanan kesehatan untuk wilayah beberapa desa di Kecamatan Mangarabombang pada tahun 2012 melaporkan bahwa dermatitis merupakan penyakit tertinggi ke dua dengan jumlah 2.431 kasus, dengan besar prevalensi $0.142 \%$ dan pada tahun 2013 jumlah kasus meningkat menjadi 2.577 dengan prevalensi sebesar $0.143 \%$. Hasil wawancara pada perawat di Puskesmas Pattopakang, pasien dermatitis 
terbanyak berasal dari Dusun Puntondo Desa Laikang yang merupakan pekerjaan utamanya sebagai petani rumput laut.

Sebuah penelitian di Dusun Puntondo menujukkan prevalensi angka kejadian dermatitis sebesar $26,6 \%$, sebagian besar dari penderita dermatitis kontak tersebut bekerja (terpapar rumput laut) lebih dari 8 jam (Fauziah dan Atjo, 2015). Penelitian mengenai kualitas hidup petani rumput laut di Dusun puntondo menujukkan hasil perhitungan statistik dengan uji chi square yaitu nilai $p<0,05$, hal ini menujukkan bahwa ada hubungan signifikan antara status kesehatan (kejadian dermatitis) dengan kualitas hidup berdasarkan dimensi kesehatan fisik, kesehatan psikologis dan dimensi lingkungan (Amalia dan Atjo, 2015).

Dermatitis merupakan gangguan kesehatan kulit pada petani rumput laut yang merupakan salah satu penyakit berbasis lingkungan. Higiene perorangan yang tidak memadai dapat mengakibatkan infeksi jamur, infeksi bakteri, virus, parasit, gangguan kulit dan keluhan lainnya. Apabila kondisi lingkungan kerja dalam keadaan kotor dan lembab, hal ini akan mengakibatkan penyakit kulit semakin lebih mudah berkembang (Nuraga dkk, 2008).

Data statistik FAO yang dirilis Maret 2015, produksi rumput laut Indonesia jenis E. cottonii pada tahun 2013, Indonesia menempati urutan pertama dunia sebanyak 8,3 juta ton. Untuk jenis Gracilaria sp., Indonesia menempati urutan kedua setelah China, dengan produksi sebesar 975 ribu ton. Total produksi rumput laut nasional telah meningkat signifikan. Dari data Kementerian Kelautan dan Perikanan, produksi rumput laut nasional tahun 2014 mencapai 10,2 juta ton, naik lebih dari tiga kali lipat dari produksi tahun 2010 yang hanya 3,9 juta ton. Dengan demikian, rata-rata pertahun naik 27,71\% (Prahadai, 2015).

Budidaya rumput laut penting perannya dalam meningkatkan produksi perikanan dalam memenuhi kebutuhan industri, memperluas kesempatan kerja dan meningkatkan pendapatan daerah (Melki dan Agussalim, 2014). Data statistik Dinas Kelautan dan Perikanan tahun 2009-2013 menujukkan peningkatan hasil produksi rumput laut dari tahun ke tahun dan pada tahun 2013 Sulawesi Selatan merupakan penghasil rumput terbanyak di Indonesia dengan jumlah produksi 2,422,154 ton (Dinas Kelautan dan Perikanan, 2014).

Dr.Msuya dalam Laporan WIEGO (Women Informal Employment Globalizing and Organizing) (2011) menyatakan bahwa petani rumput laut beresiko mengalami penyakit akibat kerja seperti kulit gatal-gatal dan infeksi pada mata akibat terkena air laut atau hewan laut berupa stonefish. Pengelolaan rumput laut seperti mengangkat ataupun menyeret dengan tidak memerhatikan aspek-aspek ergonomis sehingga pekerja mengeluh kelelahan, sakit dan nyeri pada tubuh. Adapun APD yang digunakan pada petani rumput laut untuk mengurangi risiko PAK adalah penggunaan sepatu boots, sarung tangan dan topi.

Adapun faktor-faktor yang mempengaruhi kejadian dermatitis adalah usia, jenis kelamin, ras, riwayat penyakit sebelumnya, personal hygiene dan penggunaan APD) dan lama kontak Keadaan profesi petani rumput laut yang berisiko terkena penyakit dermatitis membutuhkan perhatian karena hal ini dapat berimplikasi terhadap produktivitas kerja dan kualitas hidup bagi penderita dermatitis kontak. Bahwa berdasarkan hal tersebut di atas, masalah ini dianggap penting untuk diteliti.

\section{METODE}

Penelitian ini merupakan penelitian analitik observasional dengan rancangan Cross Sectional Study untuk menilai faktor dominan pada kejadian dermatitis kontak dan dampaknya terhadap kualitas hidup petani rumput laut. Populasi dalam penelitian ini adalah seluruh petan rumput laut yang ada di Dusun Puntondo Desa Laikang tahun 2015. Sampel adalah sebagian yang diambil dari keseluruhan objek yang diteliti dan dianggap 
memenuhi seluruh populasi. Sampel penelitian ini berjumlah 128 responden. Sampel diambil dengan teknik systematic random sampling. Untuk melihat perbedaan kualitas hidup digunakan Analisis Beda Dua Rata-rata (Comparing Means). Analisis beda dua ratarata digunakan untuk mengetahui perbedaan (difference atau biasa disingkat ) rata-rata kualitas hidup penderita dan bukan penderita dermatitis kontak. Prioritas metode analisis yang digunakan adalah uji Man Whitney untuk sampel yang tidak berpasangan. Metode ini merupakan pengujian non parametrik yang didasarkan pada asumsi sampel tidak berpasangan (independent samples) dan populasi perbedaan terdistribusi tidak normal

\section{HASIL}

Pengumpulan data baik primer maupun sekunder dilaksanakan selama 4 (empat) pekan terhitung mulai tanggal 30 Desember - 30 Januari 2015 terhadap petani rumput laut di Dusun Puntondo Desa Laikang Kabupaten Takalar.

a. Analisa Deskriptif

Tabel 1. Distribusi Karakteristik Responden Petani Rumput Laut di Dusun Puntondo Kab.Takalar Tahun 2015

\begin{tabular}{cccc}
\hline No. & Kelompok Umur (Tahun) & Nesponden & \% \\
\hline 1. & $10-19$ & 14 & 10.9 \\
2. & $20-29$ & 55 & 43.0 \\
3. & $30-39$ & 27 & 21.1 \\
4. & $40-49$ & 12 & 9.4 \\
5. & $50-59$ & 17 & 13.3 \\
6. & $60-69$ & 3 & 2.3 \\
No & Jenis Kelamin & $\mathbf{N}$ & Responden \\
1 & Laki-laki & 58 & $\mathbf{\%}$ \\
2 & Perempuan & 70 & 45.3 \\
No. & Pendidikan & $\mathbf{N}$ & 54.7 \\
1. & Tidak Sekolah & 13 & $\mathbf{\%}$ \\
2. & Tidak Tamat SD & 32 & 10.2 \\
3. & SD & 42 & 25.0 \\
4. & SMP & 25 & 32.8 \\
5. & SMA & 16 & 19.5 \\
No. & Jenis Pekerjaan & Responden & 12.5 \\
1. & Pembibitan & N & \% \\
2. & Penjemuran & 4 & 50.0 \\
3. & Keseluruhan & 60 & 3.1 \\
& Jumlah & $\mathbf{1 2 8}$ & 46.9 \\
\hline
\end{tabular}

Sumber : Data Primer, 2015

Dari Tabel 1 dapat diketahui bahwa dari pada kelompok umur $20-29$ tahun 128 responden proporsi umur terbesar adalah (43.0\%),sedangkan yang memiliki proporsi 
terendah berada pada kelompok umur 60-69 (32.8\%) dan yang paling sedikit pada tahun.

Tabel 1 juga menunjukkan bahwa dari 128 responden proporsi jenis kelamin terbesar adalah perempuan (54.7\%), sedangkan untuk pendidikan proporsi terbesar adalah SD pendidikan tidak pernah sekolah 13 orang $(10.2 \%)$. Untuk jenis pekerjaan proporsi terbesar adalah pada pembibitan $(50 \%)$ dan yang terkecil adalah penjemuran (3.1\%).

b. Analisis Bivariat

Tabel 2. Distribusi Proporsi Penderita Dermatitis Berdasarkan Variabel Independen, Nilai P, Rasio Prevalensi (RP) dengan 95\% Dusun Puntondo Kab.Takalar Tahun 2015

\begin{tabular}{|c|c|c|c|c|c|c|c|}
\hline \multirow[t]{2}{*}{ Variabel } & \multicolumn{2}{|c|}{ Penderita } & \multicolumn{2}{|c|}{$\begin{array}{c}\text { Bukan } \\
\text { Penderita }\end{array}$} & \multirow[t]{2}{*}{ Nilai p } & \multirow[t]{2}{*}{$\mathbf{R P}$} & \multirow[t]{2}{*}{ CI 95\% } \\
\hline & $\mathbf{n}$ & $\%$ & $\mathrm{n}$ & $\%$ & & & \\
\hline $\begin{array}{l}\text { Usia Responden } \\
\text { a. } \quad<25 \text { thn } \\
\text { b. } \geq 25 \text { thn }\end{array}$ & $\begin{array}{c}8 \\
26 \\
\end{array}$ & $\begin{array}{l}18.6 \\
30.6 \\
\end{array}$ & $\begin{array}{l}35 \\
59 \\
\end{array}$ & $\begin{array}{l}81.4 \\
69.4 \\
\end{array}$ & 0.147 & 0.519 & $\begin{array}{c}0.212- \\
1.274\end{array}$ \\
\hline $\begin{array}{l}\text { Lama kerja } \\
\text { a. } \geq 8 \mathrm{jam} / \mathrm{hr} \\
\text { b. }<8 \mathrm{jam} / \mathrm{hr}\end{array}$ & $\begin{array}{c}25 \\
9 \\
\end{array}$ & $\begin{array}{l}23.6 \\
40.9 \\
\end{array}$ & $\begin{array}{l}81 \\
13 \\
\end{array}$ & $\begin{array}{l}76.4 \\
59.1 \\
\end{array}$ & 0.094 & 0.446 & $\begin{array}{c}0.171- \\
1.165\end{array}$ \\
\hline $\begin{array}{l}\text { Masa Kerja } \\
\text { a. } \geq 2 \text { thn } \\
\text { b. }<2 \text { thn }\end{array}$ & $\begin{array}{c}4 \\
30 \\
\end{array}$ & $\begin{array}{l}44.4 \\
25.2\end{array}$ & $\begin{array}{c}5 \\
89 \\
\end{array}$ & $\begin{array}{l}55.6 \\
74.8 \\
\end{array}$ & 0.245 & 2.373 & $\begin{array}{c}0.598- \\
9.418 \\
\end{array}$ \\
\hline $\begin{array}{l}\text { Pendidikan } \\
\text { a. Rendah } \\
\text { b. Tinggi }\end{array}$ & $\begin{array}{c}9 \\
25\end{array}$ & $\begin{array}{r}25.7 \\
26.9 \\
\end{array}$ & $\begin{array}{l}26 \\
68 \\
\end{array}$ & $\begin{array}{l}74.3 \\
73.1 \\
\end{array}$ & 0.557 & 1.658 & $\begin{array}{c}0.442- \\
6.220 \\
\end{array}$ \\
\hline $\begin{array}{l}\text { Pengetahuan } \\
\text { a. Kurang } \\
\text { b. Baik }\end{array}$ & $\begin{array}{c}9 \\
25\end{array}$ & $\begin{array}{l}25.7 \\
26.9\end{array}$ & $\begin{array}{l}26 \\
68\end{array}$ & $\begin{array}{l}74.3 \\
73.1\end{array}$ & 0.894 & 0.942 & $\begin{array}{c}0.388- \\
2.283\end{array}$ \\
\hline $\begin{array}{l}\text { Sikap } \\
\text { a. Negatif } \\
\text { b. Positif } \\
\end{array}$ & $\begin{array}{l}10 \\
24 \\
\end{array}$ & $\begin{array}{r}26.3 \\
26.7 \\
\end{array}$ & $\begin{array}{l}28 \\
54 \\
\end{array}$ & $\begin{array}{l}73.7 \\
68.4 \\
\end{array}$ & 0.967 & 0.982 & $\begin{array}{c}0.416- \\
2.321 \\
\end{array}$ \\
\hline $\begin{array}{l}\text { Tindakan } \\
\text { a. Kurang } \\
\text { b. Baik }\end{array}$ & $\begin{array}{c}9 \\
25\end{array}$ & $\begin{array}{l}18.4 \\
31.6\end{array}$ & $\begin{array}{l}40 \\
54\end{array}$ & $\begin{array}{l}81.6 \\
68.4\end{array}$ & 0.098 & 0.486 & $\begin{array}{c}0.205- \\
1.154\end{array}$ \\
\hline $\begin{array}{l}\text { APD } \\
\text { a. Kurang } \\
\text { b. Baik } \\
\end{array}$ & $\begin{array}{c}27 \\
7 \\
\end{array}$ & $\begin{array}{l}23.1 \\
63.6 \\
\end{array}$ & 904 & $\begin{array}{l}76.9 \\
36.4 \\
\end{array}$ & 0.008 & 0.171 & $\begin{array}{c}0.047- \\
0.630\end{array}$ \\
\hline
\end{tabular}

Sumber : Data Primer , 2015

Umur merupakan salah satu faktor tinggi dermatitis adalah pasien yang berusia $\geq$ internal yang mempengaruhi kejadian 25 tahun. Hasil penelitian di Dusun Puntondo dermatitis. Usia responden dengan kejadian Kab.Takalar, sebanyak 34 orang pada dermatitis dikategorikan menjadi dua, yaitu kelompok penderita dermatitis yang ditemukan, usia $<25$ dan $\geq 25$ tahun. Usia dengan risiko diketahui 26 (30.6\%) responden yang berusia $\geq$ 
25 tahun dan 8 (18.6\%) responden yang berusia $<25$ tahun. Sedangkan 94 responden pada kelompok yang bukan penderita dermatitis dengan $42(75.0 \%)$ responden berusia $\geq 25$ tahun dan $35(81.4 \%)$ responden yang berusia $<$ 25 tahun. Pengelompokan berdasarkan umur diperoleh nilai $p=0,146$ pada $\alpha=0,05$. Karena nilai $p(0,147)>0,05$ yang berarti bahwa tidak terdapat perbedaan yang signifikan antara responden yang berusia $\geq 25$ tahun dengan $<25$ tahun terhadap kejadian dermatitis di Dusun Puntondo.

Lama kerja mempengaruhi keterpaparan pekerja terhadap material/zat/agent penyebab dermatitis. Lama kerja (jam/hari) dibagi menjadi dua kategori yakni bekerja sampai sore jika waktu bekerja $<8$ jam/hari dan dikatakan bekerja sampai malam jika petani rumput laut bekerja lebih dari $>8$ jam. Hasil penelitian di Dusun Puntondo Kab.Takalar, sebanyak 34 orang pada kelompok penderita dermatitis yang ditemukan, diketahui 25 (23.6\%) responden yang bekerja $\geq 8 \mathrm{jam} / \mathrm{hari}$ dan $9(40.9 \%)$ responden yang bekerja $<8$ jam/hari. Sedangkan 94 responden pada kelompok yang bukan penderita dermatitis dengan $81(76.4 \%)$ responden yang bekerja $\geq 8$ $\mathrm{jam} / \mathrm{hari}$ dan $13(59.1 \%)$ responden yang bekerja $<8$ jam/hari. Pengelompokan berdasarkan umur diperoleh nilai $p=0,094$ pada $\alpha=0,05$. Karena nilai $p(0,094)>0,05$ yang berarti bahwa tidak terdapat perbedaan yang signifikan antara responden yang bekerja $\geq 8$ jam/hari dan yang bekerja $<8$ jam/hari terhadap kejadian dermatitis di Dusun Puntondo.

Masa kerja adalah suatu kurun waktu atau lamanya tenaga kerja itu bekerja di suatu tempat. Semakin lama orang bekerja maka semakin besar pula risiko terkena penyakit akibat kerja (Riski, 2012). Masa kerja pada penelitian ini dikategorikan menjadi dua kelompok yaitu lama ( $\geq 2$ tahun) dan baru $(<2$ tahun). Hasil penelitian di Dusun Puntondo Kab.Takalar, sebanyak 34 orang pada kelompok penderita dermatitis ditemukan, 4
(44.4\%) responden yang masa kerjanya lama atau $\geq 2$ tahun dan $30(25.2 \%)$ responden yang bekerja baru atau $<2$ tahun. Sedangkan 94 responden pada kelompok yang bukan penderita dermatitis dengan 5 (55.6\%) responden yang masa kerjanya lama $(\geq 2$ tahun) dan $89(74.8 \%)$ responden yang masa kerjanya baru ( $<2$ tahun). Pengelompokan berdasarkan umur diperoleh nilai $p=0,245$ pada $\alpha=0,05$. Karena nilai $p(0,245)>0,05$ yang berarti bahwa tidak terdapat perbedaan yang signifikan antara responden yang masa kerjanya lama atau $\geq 2$ tahun dan yang masa kerjanya baru atau $<2$ tahun terhadap kejadian dermatitis di Dusun Puntondo. Nilai OR masa kerja $(2,337)>1$ menujukkan bahwa meskipun masa kerja tidak berpengaruh terhadap kejadian dermatitis, namun masa kerja $<2$ tahun berisiko terkena dermatitis sebesar 2 kali.

Tingkat pendidikan seseorang berbanding lurus dengan pengetahuan, semakin tinggi tingkat pendidikan seseorang maka akan semakin terbuka akses yang lebih besar untuk mendapatkan informasi. Informasi yang luas tentu saja mempengaruhi pengetahuan dan ketangkasan seseorang menyelesaikan masalah tak terkecuali mengenai kesehatan. Karena nilai $p(0,557)>0,05$ yang berarti bahwa tidak terdapat perbedaan yang signifikan antara responden yang tingkat pendidikannya rendah dan tinggi terhadap kejadian dermatitis, nilai OR pendidikan $(1,658)>1$ menujukkan bahwa meskipun tingkat pendidikan tidak berpengaruh terhadap kejadian dermatitis, namun petani rumput laut dengan pendidikan rendah berisiko terkena dermatitis sebesar 1,7 kali.

Pengetahuan merupakan hasil dari tahu, dan ini terjadi setelah orang melakukan pengindraan terhadap suatu objek tertentu (Notoadmojo, 2014). Pengetahuan pada penelitian ini dikategorikan menjadi dua kelompok yaitu kurang dan baik. Hasil penelitian di Dusun Puntondo Kab.Takalar, sebanyak 34 orang pada kelompok penderita dermatitis ditemukan $9(25.7 \%)$ responden yang tingkat pengetahuannya kurang dan 25 
(26.9\%) responden yang tingkat pengetahuannya baik. Sedangkan 94 responden pada kelompok yang bukan penderita dermatitis dengan $26(74.3 \%)$ responden yang tingkat pengetahuannya kurang dan 68 (73.1\%) responden yang tingkat pengetahuannya baik. Pengelompokan berdasarkan pengetahuan diperoleh nilai $p=0,894$ pada $\alpha=0,05$. Karena nilai $p(0,894)>0,05$ yang berarti bahwa tidak terdapat perbedaan yang signifikan antara responden yang tingkat pengetahuannya kurang dan baik terhadap kejadian dermatitis di Dusun Puntondo.

Sikap merupakan reaksi atau respon yang masih tertutup dari seseorang terhadap stimulus atau objek. Newcomb menyatakan bahwa sikap merupakan keseiapan atau kesedian untuk bertindak dan bukan pelaksanaan motif tertentu ${ }^{18}$. Sikap pada penelitian ini dikategorikan menjadi dua kelompok yaitu negatif dan positif. Hasil penelitian di Dusun Puntondo Kab.Takalar, sebanyak 34 orang pada kelompok penderita dermatitis ditemukan $10(26.3 \%)$ responden yang sikapnya negatif dan 24 (26.7\%) responden yang sikapnya positif. Sedangkan 94 responden pada kelompok yang bukan penderita dermatitis dengan 28 (73.7\%) responden yang sikapnya negatif dan 66 $(73.3 \%)$ responden yang sikapnya positif. Pengelompokan berdasarkan pengetahuan diperoleh nilai $p=0,894$ pada $\alpha=0,05$. Karena nilai $p(0,894)>0,05$ yang berarti bahwa tidak terdapat perbedaan yang signifikan antara responden yang tingkat pengetahuannya kurang dan baik terhadap kejadian dermatitis di Dusun Puntondo.

Tindakan pada penelitian ini dikategorikan menjadi dua kelompok yaitu kurang dan baik. Hasil penelitian di Dusun Puntondo Kab.Takalar, sebanyak 34 orang pada kelompok penderita dermatitis ditemukan 9 (18.4\%) responden yang tindakannya kurang dan $25(31.6 \%)$ responden yang tindakannya baik. Sedangkan 94 responden pada kelompok yang bukan penderita dermatitis dengan 40
(81.6\%) responden yang tindakannya kurang dan $54(68.4 \%)$ responden yang tindakannya baik. Pengelompokan berdasarkan tindakan diperoleh nilai $p=0,098$ pada $\alpha=0,05$. Karena nilai $p(0,098)>0,05$ yang berarti bahwa tidak terdapat perbedaan yang signifikan antara responden yang tindakannya kurang dan baik terhadap kejadian dermatitis di Dusun Puntondo.

Peraturan Menteri Tenaga Kerja dan Transmigrasi Tahun 2010 mencantumkan bahwa Alat Pelindung Diri disingkat APD adalah suatu alat yang mempunyai kemampuan untuk melindungi seseorang yang fungsinya mengisolasi sebagian atau seluruh tubuh dari potensi bahaya di tempat kerja . Alat pelindunng diri pada penelitian ini dikategorikan menjadi dua kelompok yaitu kurang dan baik. Hasil penelitian di Dusun Puntondo Kabupaten Takalar, sebanyak 34 orang pada kelompok penderita dermatitis ditemukan $27(23.1 \%)$ responden yang Alat Pelindung Diri (APD) nya kurang dan 7 $(63.3 \%)$ responden yang Alat Pelindung Dirinya (APD) baik. Sedangkan 94 responden pada kelompok yang bukan penderita dermatitis dengan $90 \quad(76.9 \%)$ responden yang Alat Pelindung Diri (APD) kurang dan 4 (36.4\%) responden yang Alat Pelindung Diri (APD) baik. Pengelompokan berdasarkan Alat Pelindung Diri (APD) diperoleh nilai $p=0,008$ pada $\alpha=0,05$. Karena nilai $p(0,008)<0,05$ yang berarti bahwa terdapat perbedaan yang signifikan antara responden yang alat pelindung dirinya kurang dan baik terhadap kejadian dermatitis di Dusun Puntondo. Nilai $(\mathrm{RP}=0.171 ; \quad \mathrm{CI}=95 \%)$ yang berarti bahwa petani rumput laut yang alat pelindung dirinya kurang dipercayai $95 \%$ berisiko terkena dermatitis 0.171 kali besar daripada petani rumput laut alat pelindung dirinya baik pada sampel yang diteliti. Sedangkan pada tingkat populasi 95\% RP terletak diantara 0.047-0.630 sehingga dapat disimpulkan bahwa benar faktor umur populasi merupakan faktor risiko untuk terjadinya dermatitis. 


\section{c. Analisis Multivariat}

Analisis multivariat dilakukan untuk beberapa variabel yang berpengaruh dengan kejadian dermatitis. Dengan menggunakan uji regresi logistik ganda bertujuan untuk mencari faktor risiko yang paling dominan berpengaruh dengan kejadian dermatitis di Dusun Puntondo Kabupaten Takalar. Meskipun demikian analisis untuk multivariate yang menggunakan uji regresi logistik oleh sebagian ahli dianggap sebagai penelitian untuk membangun hipotesis (hypothesis generating research), yang berarti hasil analisis multivariat dapat digunakan sebagai latar belakang untuk mengembangkan penelitian baru yang menguji asosiasi antara variabel independen dan variabel dependen dengan desain penelitian yang lebih sederhana dan terarah

Tabel 3. Hasil Analisis Uji Regresi Logistik Faktor yang Mempengaruhi Kejadian Dermatitis di Dusun Puntondo Kab.Takalar Tahun 2015

\begin{tabular}{|c|c|c|c|}
\hline Variabel & B & Nilai $p$ & OR \\
\hline $\begin{array}{l}\text { Usia responden } \\
\text { Lama Kerja } \\
\text { Masa Kerja } \\
\text { Tindakan } \\
\text { APD } \\
\text { Constant } \\
\text { Overall Percentage }\end{array}$ & $\begin{array}{c}- \\
0.606 \\
- \\
0.402 \\
0.854 \\
- \\
0,425 \\
- \\
1,411 \\
3.149\end{array}$ & $\begin{array}{l}0.203 \\
0.463 \\
0.248 \\
0.381 \\
0.045 \\
0.101\end{array}$ & $\begin{array}{c}0.546 \\
0.669 \\
2.350 \\
0.654 \\
0.244 \\
23.320\end{array}$ \\
\hline
\end{tabular}

Sumber : Data Primer, 2015
Didapatkan model akhir persamaan regresi logistik untuk menentukan faktor yang paling mempengaruhi kejadian dermatitis. Hasil dari regresi logistik tidak bisa langsung diinterpretasikan dari nilai koefisiennya seperti pada regresi linier. Interpretasi dapat dilakukan dengan melihat nilai dari exp (B) (nilai estimasi odds rasio) atau nilai eksponen dari koefisien persamaan regresi yang terbentuk. Secara keseluruhan model ini dapat memprediksi besar/kecilnya, tinggi/rendahnya pengaruh faktor yang ada dalam hubungannya dengan kejadian dermatitis sebesar $3.14 \%$. Jadi dari hasil regresi logistik tersebut di atas dapat disimpulkan bahwa variabel yang sangat berpengaruh dalam terjadinya dermatitis adalah penggunaan Alat Pelindung Diri (APD) dan variabel yang merupakan faktor risiko kejadian dermatitis adalah masa kerja dengan nilai OR 2,350.

\section{Kualitas Hidup}

Pada penelitian ini, dalam lembar kuesioner penelitian terdapat 24 pertanyaan mengenai kualitas hidup pasien penderita dermatitis. Pertanyaan-pertanyaan yang ada di dalam kuesioner tersebut merupakan penyesuaian daripada kuesioner WHOQOLBREF yang telah diuji validitas dan reliabilitasnya. Terdapat empat domain yaitu kesehatan fisik, kesehatan psikologis, kesehatan sosial dan kesehatan lingkungan; masingmasing akan diteliti di bawah. Semakin tinggi skor untuk suatu domain, semakin baik kualitas hidup berdasarkan domain tersebut 
Tabel 4. Skor Dimensi Kualitas Hidup Penderita Dermatitis dan Tidak Menderita Dermatitis di Dusun Puntondo Kab.Takalar Tahun 2015

\begin{tabular}{|c|c|c|c|c|c|c|c|c|c|}
\hline \multirow{3}{*}{ No } & \multicolumn{8}{|c|}{ Kesehatan Fisik } & \multirow{3}{*}{$\mathbf{P}$} \\
\hline & Dermatitis & \multicolumn{2}{|c|}{ Buruk } & \multicolumn{2}{|c|}{ Baik } & \multirow[t]{2}{*}{$\begin{array}{l}\text { Min- } \\
\max \end{array}$} & \multirow[t]{2}{*}{ Mean } & \multirow[t]{2}{*}{ SD } & \\
\hline & & $\mathbf{n}$ & $\%$ & $\mathbf{n}$ & $\%$ & & & & \\
\hline 1 & $\mathrm{Ya}$ & 30 & 88.2 & 4 & 11.8 & $15-24$ & 7.173 & 1.230 & \multirow[b]{2}{*}{0.0000} \\
\hline 2 & Tidak & 24 & 25.5 & 70 & 74.5 & $16-29$ & 7.569 & 0.781 & \\
\hline \multicolumn{10}{|c|}{ Kesehatan Psikologis } \\
\hline 1 & $\mathrm{Ya}$ & 27 & 79.4 & 7 & 20.6 & $12-24$ & 2,501 & 0,429 & \multirow[b]{2}{*}{$0.000 *$} \\
\hline 2 & Tidak & 18 & 19.1 & 76 & 80.9 & $16-26$ & 2.395 & 0,247 & \\
\hline \multicolumn{10}{|c|}{ Hubungan Sosial } \\
\hline 1 & $\mathrm{Ya}$ & 12 & 35.3 & 22 & 64.7 & $6-13$ & 2.246 & 0.385 & \multirow[b]{2}{*}{$0.012 *$} \\
\hline 2 & Tidak & 24 & 25.5 & 70 & 74.5 & $6-15$ & 1.997 & 0.206 & \\
\hline \multicolumn{10}{|c|}{ Kesehatan Lingkungan } \\
\hline 1 & $\mathrm{Ya}$ & 31 & 91.2 & 3 & 8.8 & $16-29$ & 1.707 & 0.293 & \multirow[b]{2}{*}{$0.000 *$} \\
\hline 2 & Tidak & 23 & 24.5 & 71 & 75.5 & $19-34$ & 2.037 & 0.210 & \\
\hline \multicolumn{10}{|c|}{ Kualitas Hidup } \\
\hline 1 & $\mathrm{Ya}$ & 8 & 23.5 & 26 & 76.5 & $64-91$ & 3.088 & 0.530 & \multirow[t]{2}{*}{0.000} \\
\hline 2 & Tidak & & & 94 & 100.0 & $74-107$ & 2.948 & 0.304 & \\
\hline
\end{tabular}

Sumber : Data Primer , 2015

Tabel 4 menunjukkan bahwa nilai rata-rata kesehatan fisik pada petani rumput laut yang tidak menderita dermatitis adalah sebesar 7.569 sedangkan yang menderita dermatitis adalah sebesar 7.173. Pada kesehatan psikologis ratarata skor pada petani rumput laut yang tidak menderita dermatitis adalah sebesar 2.395 sedangkan pada petani rumput laut yang 
menderita dermatitis rata-rata skor kesehatan psikologis adalah sebesar 2.501. Pada kesehatan sosial rata-rata skor yang diperoleh pada petani rumput laut yang tidak menderita dermatitis adalah sebesar 1.997 sedangkan pada petani rumput laut yang menderita dermatitis diperoleh rata-rata sebesar 2.246. Pada kesehatan lingkungan, rata-rata skor pada petani rumput laut yang tidak menderita dermatitis adalah sebesar 2.037 sedangkan pada petani rumput laut yang menderita dermatitis rata-rata skor yang diperoleh adalah sebesar 1,707 . Nilai rata-rata kualitas hidup pada petani rumput laut yang tidak menderita dermatitis sebesar 2.948 sedangkan yang menderita dermatitis adalah sebesar 3.088.

Dari hasil uji statistik menunjukkan bahwa keempat dimensi kualitas hidup tersebut bermakna karena nilai $\mathrm{p} \leq 0.05$ yang berarti bahwa ada perbedaan skor kesehatan fisik, kesehatan psikologis, kesehatan sosial, kesehatan lingkungan dan kualitas hidup pada petani rumput laut yang menderita dermatitis dan yang tidak menderita dermatitis. Kualitas hidup petani rumput laut yang mengalami dermatitis lebih rendah dibandingkan petani yang tidak mengalami dermatitis

\section{PEMBAHASAN}

Persentase dermatitis akibat kerja dari seluruh penyakit akibat kerja menduduki porsi tertinggi sekitar $50-60 \%$. Selain prevalensi yang tinggi, lokasi kelainan dermatitis akibat kerja biasanya terdapat pada lengan, tangan dan jari (Nigtiyas, 2013). Pada populasi umum, prevalensi DKA pada orang dewasa berkisar 26$40 \%$ dan pada anak-anak berkisar $13-37 \%$, serta pada orang yang terkena seumur hidup berkisar 10\% (Spiewak, 2008).

Menurut Gilles L, Evan R, Farmer dan Antoniette (1990) ras kulit hitam lebih tahan terhadap penyakit kulit tipe kulit berminyak lebih tahan terhadap sabun, bahan dan zat-zat yang larut dalam air, sedangkan kulit yang kering tahan terhadap chemical dehydration, keringat dapat pula merubah bahan-bahan yang larut dalam air menjadi bentuk lain dan mempermudah absrobsi kulit melalui pori-pori kulit, dermatitis akibat kerja banyak dijumpai pada waktu musim panas karena pengeluaran keringat meningkat dan pekerja kurang senang memakai Alat Pelindung Diri (APD), cuaca dingin pun dapat meningkatkan kejadian dermatitis apabila pekerja malas membersihkan diri dengan air setelah kontak dengan zat kimia, perilaku, berupa aksi kerja melaku kan pekerjaan. Meskipun pekerja sudah mengetahui prosedur kerja dan resiko kerja, namun pekerja belum tentu bertindak sesuai dengan pengetahuan yang dimillikinya.

Menurut Suryani (2011) dalam penelitiannya menyebutkan jenis kelamin merupakan salah satu faktor yang dapat menyebabkan terjadinya dermatitis kontak. Terdapat perbedaan antara kulit pria dengan wanita, perbedaan tersebut terlihat dari jumlah folikel rambut, kelenjar keringat dan hormon. Kulit wanita memproduksi lebih sedikit minyak untuk melindungi dan menjaga kelembapan kulit sehingga lebih kering daripada pria, selain itu juga kulit wanita lebi tipis daripada kulit pria sehingga lebih rentan untuk menderita penyakit dermatitis.

Berdasarkan hasil pengolahan data, diperoleh informasi angka kejadian dermatitis pada petani rumput laut di Dusun Puntondo sebesar $26.6 \%$.

1. Faktor yang mempengaruhi kejadian dermatitis

a. Umur dan kejadian dermatitis

Menurut Hayakawa (2000) Secara normal semakin bertambah umur seseorang maka semakin rendah kemampuan imun atau kekebalan tubuh manusia terhadap berbagai serangan atau paparan dari luar tubuh. Umur merupakan salah satu unsur yang tidak dapat dipisahkan dari individu. Selain itu usia juga merupakan salah satu faktor yang dapat memperparah terjadinya dermatitis (Mariz, 2014).

Setelah melakukan penelitian diperoleh informasi mengenai hubungan antara umur 
dengan kejadian dermatitis. Dari hasil tabulasi silang antara umur responden dengan kejadian dermatitis diperoleh informasi bahwa jumlah responden dengan kelompok umur $\geq 25$ tahun yang menderita dermatitis adalah sebanyak 26 responden (30.6\%), lebih banyak jika dibandingkan dengan penderita dermatitis dengan kelompok umur responden $<25$ tahun yang hanya sebanyak 8 responden (18.6\%).

Berdasarkan uji statistik chi-square diketahui bahwa tidak terdapat hubungan antara umur responden terhadap kejadian dermatitis dengan nilai $\mathrm{p}>0.05$ yang berarti bahwa hipotesis null diterima. Sehingga dapat disimpulkan bahwa tidak ada hubungan antara umur dan kejadian dermatitis.

Hasil penelitian ini sejalan dengan penelitian Angkit Oktavanni (2009) mengenai faktor-faktor yang berhubungan dengan dermatitis kontak iritan pada karyawan pabrik pengolahan aki bekas di lingkungan industri kecil (LIK) Semarang menyatakan bahwa tidak ada hubungan antar umur dan dermatitis. Dalam penelitian Suwondo dkk (2012) mengenai faktor-faktor yang berhubungan dengan kejadian dermatitis kontak pekerja industri tekstil "x" di Jepara menyatakan bahwa ada hubungan signifikan antara umur dan kejadian dermatitis.

Meskipun pada hasil analisis bivariat didapatkan bahwa umur tidak berpengaruh pada kejadian dermatitis, namun dari jumlah 34 penderita dermatitis $26(76.4 \%)$ diantara berada pada kelompok umur $\geq 25$.

Usia tua menyebabkan tubuh lebih rentan terhadap bahan iritan. Seringkali pada usia lanjut terjadi kegagalan dalam pengobatan dermatitis sehingga timbul dermatosis kronik. Dapat dikatakan bahwa dermatosis akan lebih mudah menyerang pada usia yang lebih tua (Trihapsoro, 2003) Cohen yang menyatakan bahwa kulit manusia mengalami degenerasi seiring bertambahnya usia, sehingga menyebabkan penipisan pada lapisan lemak dibawah kulit akibatnya kulit menjadi lebih kering dan mudah teriritasi menjadi dermatitis kontak (Suwondo, 2012).

\section{Lama kerja dan kejadian dermatitis}

Setelah melakukan penelitian diperoleh informasi mengenai hubungan antara umur dengan kejadian dermatitis. Dari hasil tabulasi silang antara lama kerja responden dengan kejadian dermatitis diperoleh informasi bahwa jumlah responden dengan kelompok lama kerja $\geq 8 \mathrm{jam} /$ hari (lama) yang menderita dermatitis adalah sebanyak 25 responden (23.6\%), jumlah ini lebih banyak jika dibandingkan dengan penderita dermatitis dengan kelompok lama kerja $<8 \mathrm{jam} / \mathrm{hari}$ (tidak lama) yang sebanyak 9 responden (40.9\%).

Berdasarkan uji statistik chi-square diketahui bahwa tidak terdapat hubungan antara lama kerja responden terhadap kejadian dermatitis dengan nilai $\mathrm{p}>0.05$ yang berarti bahwa hipotesis null diterima. Sehingga dapat disimpulkan bahwa tidak ada hubungan antara lama kerja dan kejadian dermatitis.

Hasil penelitian ini sejalan dengan penelitian Newhouse mengenai Dogger Bank Itch: Survey of trawlermen (1966) menyatakan bahwa tidak ada hubungan signifikan antara lama kerja dan kejadian dermatitis. Dalam penelitian Mariz dkk (2014) mengenai faktor-faktor yang mempengaruhi kejadian dermatitis kontak akibat kerja pada karyawan pencucian mobil di Kelurahan Sukarame Kota Bandar Lampung yang menyatakan bahwa ada pengaruh lama kerja terhadap kejadian dermatitis.

Meskipun berdasarkan uji statistik dalam penelitian ini tidak ditemukan adanya pengaruh lama kerja terhadap kejadian dermatitis, namun hasil tabulasi silang terlihat bahwa dari 34 penderita 
dermatitis $25 \quad(73.5 \%)$ di antaranya memiliki lama kerja $\geq 8 \mathrm{jam} /$ hari. Hasil penelitian Azhar dan Hananto (2011) mengenai hubungan proses kerja dengan kejadian dermatitis kontak iritan pada petani rumput di Kabupaten Bantaeng menyatatakan bahwa kelompok dengan waktu kerja lebih dari 8 jam sehari jumlah dermatitis lebih banyak (64.5\%) dibanding dengan waktu kerja kurang dari 8 jam sehari (52.7\%).

Lama kerja antar pekerja berbeda, sesuai dengan proses pekerjaannya. Lama kerja mempengaruhi keterpaparan dan dapat menyebabkan kejadian dermatitis kontak akibat kerja. Semakin lama terpapar dengan pekerjaanya maka peradangan atau iritasi kulit dapat terjadi sehingga menimbulkan kelainan kulit (Eidman, 2008).

$$
\text { Penelitian }
$$

menyarankan

Ngajilo frekuensi dan lama kontak dengan material/zat/agent penyakit menjadi salah satu pengendalian yang dapat menurunkan risiko terkena dermatitis. Membatasi waktu kerja perhari merupakan salah satu pengendalian yang harus dilakukan oleh pekerja, hanya saja kurangnya pengetahuan pekerja mengenai risiko dan bahaya bertani rumput laut sehingga hal ini sulit untuk diterapkan.

b. Masa kerja dan kejadian dermatitis

Hasil tabulasi silang antara masa kerja responden dengan kejadian dermatitis diperoleh informasi bahwa jumlah responden dengan kelompok masa kerja $<2$ tahun (baru) yang menderita dermatitis adalah sebanyak 30 responden (25.2\%),jumlah ini lebih banyak jika dibandingkan dengan penderita dermatitis dengan kelompok masa kerja $\geq 2$ tahun (lama) yang hanya sebanyak 4 responden (44.4\%).

Berdasarkan uji statistik chi-square diketahui bahwa tidak terdapat pengaruh variabel masa kerja responden terhadap kejadian dermatitis dengan nilai $\mathrm{p}>0.05$ yang berarti bahwa hipotesis null diterima. Hasil penelitian ini sejalan dengan penelitian Suhelmi dkk (2014) mengenai hubungan masa kerja, higiene perorangan dan penggunaan alat pelindung diri dengan keluhan gangguan kulit petani rumput laut di Kelurahan Kalumeme Bulukumba. 2014, dimana dinyatakan bahwa tidak ada pengaruh masa kerja terhadap kejadian dermatitis.

Hasil penelitian Lestari dan Utomo (2007) mengenai Faktor-faktor yang berhubungan dengan dermatitis kontak pada pekerja di PT Inti Pantja Press Industri. mendapatkan hasil yang berbeda dimana terdapat hubungan signifikan antara masa kerja dan kejadian dermatitis dengan persentase masa kerja $<2$ tahun lebih banyak yang terkena dermatitis yaitu sebanyak 22 orang $(66,7 \%)$, dibandingkan dengan 17 orang $(36,2 \%)$ dari 47 pekerja yang bekerja $\geq 2$ tahun dan nilai OR 3,5.

Pada tabel 2 menujukkan bahwa nilai OR masa kerja $(2,337)>1$ yang berarti bahwa petani rumput laut dengan masa kerja $<2$ tahun berisiko terkena dermatitis sebesar 2 kali lipat dari pada petani rumput laut yang masa kerjanya $\geq 2$ tahun. Meskipun secara statistik variabel masa kerja pada penelitian menujukkan tidak berpengaruh terhadap kejadian dermatitis, namun angka persentase dari 34 responden yang menderita dermatitis $30(88.2 \%)$ di antaranya memiliki masa kerja $<2$ tahun.

Pekerja dengan lama kerja $<2$ tahun dapat menjadi salah satu faktor yang mengindikasikan bahwa pekerja tersebut belum memiliki pengalaman yang cukup dalam melakukan pekerjaanya. Jika pekerja ini masih sering ditemui melakukan kesalahan, maka hal ini berpotensi meningkatkan angka kejadian dermatitis. Pekerja dengan pengalaman akan lebih berhati-hati sehingga 
kemungkinan terpajan bahan iritan maupun alergen lebih sedikit.

Pada pekerja dengan lama bekerja $>$ 2 tahun dapat dimungkinkan telah memiliki resistensi terhadap bahan iritan maupun alergen. Untuk itulah mengapa pekerjaan dengan lama bekerja $>2$ tahun lebih sedikit yang mengalami dermatitis kontak (Lestari dan Utomo, 2007). Lama kontak akan menyebabkan makin meningkatnya reaksi peradangan atau kelainan kulit yang terjadi (Garmini, 2014).

c. Pendidikan dan kejadian dermatitis

Hasil penelitian menujukkan informasi mengenai hubungan antara pendidikan dengan kejadian dermatitis. Dari hasil tabulasi silang antara pendidikan responden dengan kejadian dermatitis diperoleh informasi bahwa jumlah responden dengan kelompok pendidikan rendah yang menderita dermatitis adalah sebanyak 31 responden (27.7\%), jumlah ini lebih banyak jika dibandingkan dengan penderita dermatitis dengan kelompok pendidikan tinggi hanya sebanyak 3 responden $(18.8 \%)$.

Berdasarkan uji statistik chi-square diketahui bahwa tidak terdapat hubungan antara pendidikan responden terhadap kejadian dermatitis dengan nilai $\mathrm{p}>0.05$ yang berarti bahwa hipotesis null diterima. Sehingga dapat disimpulkan bahwa tidak ada hubungan antara pendidikan dan kejadian dermatitis.

Hasil penelitian ini sejalan denngan penelitian Farida (2011) mengenai hubungan antara pengetahuan tentang dermatitis pendidikan dan pekerjaan dengan kejadian dermatitis kontak alergik di Puskesmas Turi Sleman DIY yang menyatakan bahwa tidak ada hubungan antar tingkat pendidikan dengan kejadian dermatitis. Berbeda dengan hasil penelitian Pracoyo (2013) mengenai faktor - faktor yang berhubungan dengan penyakit dermatitis alergika berdasarkan
Riskesdas di Indonesia 2007 yang menyatakan ada pengaruh tingkat pendidikan terhadap kejdian dermatitis.

Pada tabel 2 menujukkan bahwa nilai OR tingkat pendidikan $(1,658)>1$ menujukkan bahwa petani rumput laut dengan tingkat pendidikan rendah memiliki peluang terkena dermatitis 1,7 kali dibandingkan petani rumput laut dengan pendidikan tinggi. Meskipun secara statistik variabel tingkat pendidikan pada penelitian menujukkan tidak berpengaruh terhadap kejadian dermatitis, namun angka persentase dari 34 responden yang menderita dermatitis $31 \quad(91.1 \%)$ di antaranya memiliki pendidikan rendah.

Tingkat pendidikan seseorang dapat meningkatkan pengetahuan seseorang termasuk tingkat pengetahuan mengenai kesehatan. Semakin rendah tingkat pengetahuan semakin besar seseorang beresiko mengalami penyakit kulit(Suhelmi, 2014). Rendahnya tingkat pendidikan berpengaruh terhadap perilaku kebersihan yang dapat mencegah terjadinya DKAK (Luwia, 1994).

d. Pengetahuan dan kejadian dermatitis

Hasil tabulasi silang antara pengetahuan responden dengan kejadian dermatitis diperoleh informasi bahwa jumlah responden dengan kelompok kurang, yang menderita dermatitis adalah sebanyak 9 responden $(25.7 \%)$, jumlah ini lebih sedikit jika dibandingkan dengan penderita dermatitis dengan kelompok pengetahuan baik yang sebanyak 25 responden $(26.9 \%)$.

Berdasarkan uji statistik chi-square diketahui bahwa tidak terdapat hubungan antara pengetahuan responden terhadap kejadian dermatitis dengan nilai $\mathrm{p}>0.05$ yang berarti bahwa hipotesis null diterima. Sehingga dapat disimpulkan bahwa tidak ada hubungan antara pengetahuan dan kejadian dermatitis. 
Hasil penelitian ini sejalan dengan penelitian Djewarut (2012) mengenai hubungan pengetahuan dan perilaku dengan kejadian dermatitis kontak di Puskesmas Canga di Kecamatan Liriaja Kabupaten Soppeng ${ }^{34}$. Pada penelitian Situmeang (2008) mengenai analisis dermatitis kontak pada pekerja pencuci di PT X Medan menyebutkan hal sama bahwa tidak ada hubungan antar pengetahuan dan kejadian dermatitis.

Hasil penelitian Shafik dan ElMohsen (2012) menyebutkan bahwa bahwa hampir dua pertiga dari 350 respondennya memiliki pengetahuan rendah $(67.1 \%)$ mengenai penyakit akibat kerja dan dari total sampel didapatkan kerja $65.7 \%$ menderita gangguan kulit akibat kerja. Penelitian Tunsaringkan dkk (2012) mengenai pengetahuan untuk meningkatkan tindakan aman pekerja menujukkan bahwa perubahan pengetahuan pekerja yang menjadi lebih baik mampu mempengaruhi tindakan pekerja menjadi lebih baik pula, dimana pekerja sadar untuk mengatur jam kerja dan senantiasa menggunakan alat pelindung diri saat bekerja.

Seorang pekerja yang mengetahui dan mengenali lingkungan kerjanya lebih berpeluang besar untuk mengendalikan faktor bahaya di sekitarnya. Namun, sebagian Pekerja yang tidak mengetahui bagimana prosedur kerja yang baik dan dan menghindarkannya dari penyakit akibat kerja ataupun kecelakaan kerja(Fauziah dan Atjo, 2015).

e. Sikap dan kejadian dermatitis

Setelah melakukan penelitian diperoleh informasi mengenai hubungan antara sikap dengan kejadian dermatitis. Dari hasil tabulasi silang antara sikap responden dengan kejadian dermatitis diperoleh informasi bahwa jumlah responden dengan kelompok sikap positif dari yang menderita dermatitis adalah sebanyak 24 responden (26.7\%), jumlah ini lebih banyak jika dibandingkan dengan penderita dermatitis dengan kelompok sikap negatif yaitu sebanyak 10 responden $(26.3 \%)$.

Berdasarkan uji statistik chi-square diketahui bahwa tidak terdapat hubungan antara sikap responden terhadap kejadian dermatitis dengan nilai $\mathrm{p}>0.05$ yang berarti bahwa hipotesis null diterima. Sehingga dapat disimpulkan bahwa tidak ada hubungan antara sikap dan kejadian dermatitis.

Hasil penelitian ini sejalan dengan penelitian Nugraheni dan Maliya (2012) mengenai pengaruh sikap dengan timbulnya skabies, menyebutkan bahwa ada hubungan antar sikap yanng baik dengan timbulya scabies. Namun, berbeda dengan penelitian sebelumnya, penelitian Fauziah dan Atjo (2015) mengenai hubungan lama kontak dan perilaku kerja terhadap kejadian dermatitis pada petani rumput laut di Dusun Puntondo menyebutkan bahwa ada pengaruh sikap terhadap kejadian dermatitis.

Salah seorang ahli psikologi sosial menyatakan bahwa sikap itu merupakan kesiapan atau kesediaan untuk bertindak dan bukan merupakan pelaksanaan motif tertentu. Allport (1954) dalam Notoadmodjo (2012) menjelaskan bahwa sikap memiliki tiga komponen yakni kepercayaan, kehidupan emosional dan kecenderungan untuk bertindak, ketiga komponen membentuk sikap yang utuh (total attitude). Sikap merupakan penilaian seseorang terhadapp stimulus atau objek, setelah mengetahui stimulus selanjutnya menilai sesuai dengan pengetahuan.

f. Tindakan dan kejadian dermatitis

Setelah melakukan penelitian diperoleh informasi mengenai hubungan antara tindakan dengan kejadian 
dermatitis. Dari hasil tabulasi silang antara tindakan responden dengan kejadian dermatitis diperoleh informasi bahwa jumlah responden dengan kelompok tindakan baik dari yang menderita dermatitis adalah sebanyak 25 responden $(31.6 \%)$, jumlah ini lebih banyak jika dibandingkan dengan penderita dermatitis dengan kelompok tindakan kurang yaitu sebanyak 9 responden (18.4\%).

Berdasarkan uji statistik chi-square diketahui bahwa tidak terdapat hubungan antara tindakan responden terhadap kejadian dermatitis dengan nilai $\mathrm{p}>0.05$ yang berarti bahwa hipotesis null diterima. Sehingga dapat disimpulkan bahwa tidak ada hubungan antara tindakan dan kejadian dermatitis.

Hasil penelitian ini berbeda dengan hasil penelitian Situmeang (2008) mengenai analisis dermatitis kontak pada pencuci botol di PT X Medan menyebutkan bahwa ada pengaruh tindakan pekerja terhadap kejadian dermatitis. Tindakan sejalan dengan tingkat pengetahuan. Ketika seseorang memiliki tingkat pengetahuan baik maka tindakannya pun akan baik. Pada penelitian Yassin et.al (2002) mengenai pengetahuan, sikap, dan praktek terhadap toksisitas penggunaan pestisida Petani di jalur Gaza yang menyebutkan bahwa semua yang memiliki tindakan pencegahan seperti penggunaan sarung tangan, masker, sepatu, topi dan alat pelindung diri lainya memiliki pengetahuan yang baik mengenai nama dan efek dari pestisida.

g. Alat pelindung diri dan kejadian dermatitis

Hasil tabulasi silang antara Alat Pelindung Diri (APD) responden dengan kejadian dermatitis diperoleh informasi bahwa jumlah responden dengan kelompok APD baik dari penderita dermatitis adalah sebanyak 27 responden (23.1\%), jumlah ini lebih banyak daripada kelompok APD baik sebanyak 7 responden (63.6\%).

Berdasarkan uji statistik chi-square diketahui bahwa terdapat hubungan antara APD responden terhadap kejadian dermatitis dengan nilai $\mathrm{p}<0.05$. Meskipun secara statistik didapatkan bahwa ada pengaruh penggunaan APD terhadap kejadian dermatitis pada petani rumput laut di Dusun Puntondo, namun Tabel 2 menujukkan nilai OR APD sebesar $0.171<1$ yang berarti bahwa penggunaan APD bukan merupakan faktor risiko kejadian dermatitis. Namun, penggunaan APD merupakan upaya pencegahan dan perlindungan agar terhindar dari kejadian dermatitis.

Hasil penelitian ini sejalan dengan penelitian Cahyawati (2011) mengenai faktor yang berhubungan dengan kejadian dermatitis pada nelayan yang memaparkan bahwa ada pengaruh penggunaan APD terhadap kejadian dermatitis. Namun, penelitian Lestari dan Utomo (2007) mengenai faktor-faktor yang berhubungan dengan dermatitis kontak pada pekerja di PT PIP menyebutkan bahwa tidak ada pegaruh penggunaan APD terhadap kejadian dermatitis, hal ini dikarenakan para pekerja tidak menggunakan APD dengan baik sehingga kulit masih kontak dengan bahan iritan.

Secara sederhana yang dimaksud dengan APD adalah seperangkat alat yang digunakan oleh tenaga kerja untuk melindungi sebagian atau seluruh tubuhnya dari potensi bahaya kecelakaan kerja (Lestari dan Utomo, 2007). Pemakaian APD yang tidak tepat dapat mencelakakan tenaga kerja yang memakainya karena mereka tidak terlindung dari bahaya potensial yang ada di tempat mereka terpapar. Oleh karena itu agar dapat memilih APD yang tepat, maka perusahaan harus mampu 
mengidentifikasi bahaya potensi yang ada, khususnya yang tidak dapat dikendalikan, serta memahami dasar kerja setiap jenis APD yang akan digunakan di tempat kerja dimana bahaya potensial tersebut ada (Yassin et.al, 2002).

Untuk meningkatkan kesadaran pekerja dalam penggunaan alat pelindung diri dibutuhakn edukasi seperti yang dilakukan oleh Tunsaringkarn dkk (2012), dimana setelah melakukan penyuluhan peningkat an pengetahuan dari $34.1 \%$ menjadi $85.4 \%$ dan penggunaan APD dari $7,5 \%$ menjadi $85.4 \%$.

\section{Kualitas Hidup Petani Rumput Laut}

World Health Organization
Quality of Life (WHOQoL)

mendefinisikan bahwa kualitas hidup merupakan persepsi individu terhadap posisi mereka dalam hidup ditinjau dari konteks budaya dan sistem nilai dimana mereka tinggal dan berhubungan dengan standar hidup, harapan, kesenangan serta perhatian mereka(Archietobias et.al 2014).

Adapun menurut Cohen dan Lazarus, kualitas hidup adalah tingkatan yang menggambarkan keunggulan seorang individu yang dapat dinilai dari kehidupan mereka. Kualitas hidup individu tersebut biasanya dapat dinilai dari kondisi fisiknya, psikologis, hubungan sosial dan lingkungannya (Chairani, 2013).

$$
\text { Pada penelitian mengenai }
$$

kualitas hidup penderita dermatitis ini didapatkan informasi dengan uji statistik chi-square dimana terdapat hubungan antara kualitas hidup dengan kejadian dermatitis dengan nilai $\mathrm{p}<$ 0.05 .

Adapun $p$ value dimensi-dimensi kualitas hidup lainnya, keempatnya memiliki nilai $p<0.05$, mulai dari kesehatan fisik $(p=0,000)$ menggunakan uji chi-square, dan tiga dimensi lainnya menggunakan uji statistik mann whitney yaitu dimensi kesehatan psikologis (0.000), hubungan sosial $(0,012)$ dan kesehatan lingkungan $(0,000)$.

Berdasaran nilai statistik dimensi kualitas hidup yang tersebut menujukkan bahwa kualitas hidup petani rumput dengan penyakit dermatitis memiliki kualitas lebih rendah dibandingkan petani rumput yang non dermatitis, meliputi dimensi kesehatan fisik, kesehatan psikologis, hubungan sosial dan kesehatan lingkungan.

Dermatitis merupakan kelainan kulit yang subyektif ditandai rasa gatal dan bersifat kambuh-kambuhan yang mengakibatkan ketidaknyamanan terhadap penderitanya. Berdasarkan hasil penelitian, dilihat dari segi kesehatan fisik, dalam keseharian responden dalam menjalankan aktifitas/pekerjaannya mereka merasa terganggu disebabkan karena rasa gatal yang dirasakan sehingga dapat menghambat pekerjaan mereka, responden mengeluhkan terkadang saat bekerja mereka menggaruk bagian kulit yang terasa gatal dengan keadaan tangan/kuku yang kotor sehingga akan memperparah bagian kulit tersebut.Kesulitan dalam hal istrahat/tidur yang diakibatkan rasa gatal yang dirasakannya sehingga waktu istrahat mereka berkurang atau kurang dari waktu istrahat pada umumnya ( 8 jam) perhari. Hal ini akan berdampak pada kemampuan/produktifitas petani rumput laut dalam menjalankan aktifitas sehari-hari (Amalia dan Atjo, 2015).

Hasil penelitian ini sejalan dengan penelitian yang mengatakan bahwa dermatitis merupakan kondisi kulit kronis yang dapat memiliki dampak negatif pada kualitas hidup seseorang, yang mempengaruhi mereka 
secara fisik. Ketidaknyamanan fisik, stigmatisasi, kehilangan produktifitas, merasa rendah diri dan keterbatasan dalam kegiatan sehari-hari (Ahmed et.al, 2013).

Dermatitis juga mempengaruhi kesehatan psikologis. Dampak dari lesi kulit akibat aspek yang terlihat memiliki implikasi psikologis yang besar. Studi telah mengidentifikasi masalah seperti perasaan malu, kecemasan, rasa percaya diri yang rendah. Penilaian gangguan suasana hati yang besar sebagai kecemasan, depresi, perubahan suasana hati, harga diri atau stigmatisasi juga ditemukan dalam penderita dermatitis (Coghi et.al , 2007).

Penelitian Ravi

menyebutkan bahwa pada penderita kelainan kulit memberikan dampak psikologis sangat besar pengaruhnya terhadap pasien perempuan daripada pasien laki-laki. Bahkan keinginan bunuh diri ditemukan sekitar $6-7 \%$ pada penderita kelainan kulit.

Hubungan sosial terutama dukungan sosial sangat berpengaruh terhadap kesehatan psikologis seseorang. Dukungan sosial dapat mengurangi tekanan psikologis yang terjadi pada individu yang menderita penyakit kulit (Andri, 2011). Hasil penelitian ini sejalan dengan Kahneman, Diener dan Schwarz dalam (Nofitri, 2009) yang mengatakan bahwa pada saat kebutuhan akan hubungan dekat dengan orang lain terpenuhi, baik melalui hubungan pertemanan yang saling mendukung maupun melalui pernikahan, manusia akan memiliki kualitas hidup yang lebih baik.

Kualitas hidup penderita dermatitis dalam dimensi lingkungan mencakup Dimensi lingkungan mencakup financial/penghasilan, lingkungan rumah, pelayanan kesehatan, informasi yang didapatkan, kesempatan berekreasi atau kegiatan yang menyenangkan dan transportas i(Amalia dan Atjo, 2015).

Dengan penghasilan yang rendah sebagian besar responden baik yang berstatus kesehatan dermatitis maupun non dermatitis memiliki keterbatasan untuk melakukan kegiatan menyenangkan seperti rekreasi serta mengunjungi rumah sakit untuk berobat bagi responden yang memiliki penyakit serius/dermatitis. Selain itu sarana dan prasarana yang tersedia sangat sulit didapatkan oleh mereka, dalam hal transportasi yang sangat terbatas sehingga mereka sulit untuk mendapatkan pelayanan kesehatan yang lebih baik, mereka hanya mengandalkan bidan di dusun untuk berobat. Didasari oleh penghasilan yang rendah lingkungan fisik/kondisi rumah responden juga yang masih jauh dikatakan sempurna dan dalam keadaan lingkungan rumah yang kotor (Amalia dan Atjo, 2015).

Adanya perbedaan kualitas hidup antara penderita dermatitis dan non dermatitis pada petani rumput laut di Dusun Puntondo terbukti baik secara uji statistik maupun keadaan di lapangan dan didukung oleh penelitian serta teori-teori yang ada. Perbedaan kualitas hidup dari berbagai dimensi.

\section{KESIMPULAN DAN SARAN}

Berdasarkan analisis bivariat diketahui bahwa hanya variabel APD yang berpengaruh terhadap kejadian dermatitis $(p=0,008)$ tetapi bukan faktor risiko dermatitis karena nilai OR nya $<1$.

Faktor masa kerja $(\mathrm{OR}=2,37)$ dan pendidikan $(\mathrm{OR}=1,66)$ merupakan faktor risiko kejadian dermatitis. Secara simultan variabel yang berpengaruh terhadap kejadian dermatitis adalah APD, tetapi yang paling berisiko 
terhadap kejadian dermatitis adalah masa kerja dengan nilai OR 2,35.Kualitas hidup petani rumput laut yang mengalami dermatitis lebih rendah dibandingkan petani yang tidak mengalami dermatitis. Diharapkan kepada pihak pemerintah agar memperhatikan kondisi kesehatan pekerja non-formal di wilayah pesisir, yang memiliki potensi besar dalam meningkatkan perekonomian negara dengan cara membuat kelompok tani khusus petani rumput laut untuk memudahkan peningkatan edukasi dan pengawasan pada pekerja.

\section{DAFTAR PUSTAKA}

Ahmed A, Leon A, Butler DC, Reichenberg J. 2013. Quality-of-Life Effects of Common Dermatological Diseases. Semin Cutan Med Surg. 32(2):101-9.

Amalia A, Atjo W. 2015. Hubungan Kejadian Dermatitis dengan Kualitas Hidup pada Petani Rumput Laut di Dusun Puntondo Kabupaten Takalar. Universitas Hasanuddin. Makassar.

Andri A, Kusumawardhani A, Sudharmono A. 2011. The Association of Selfconsciousness and Low Self Esteem to Quality of Life Among Acne Patients. Journal of the Indonesian Medical Association. 60(06).

Archietobias MA, Sibero HT, Carolia N. 2014. Hubungan antara Derajat Keparahan Dermatitis Atopik dengan Kualitas Hidup Pasien di RSUD Abdul Moeloek Lampung. Majority. 3(4).

Azhar, K. \& Hananto, M. 2011. Hubungan Proses Kerja dengan Kejadian Dermatitis Kontak Iritan Pada Petani Rumput Laut di Kabupaten Bantaeng Sulawesi Selatan. Jurnal Ekologi Kesehatan, 10.

Cahyawati, Imma Nur IB. 2011. Faktor yang Berhubungan dengan Kejadian Dermattitis pada

Nelayan. Jurnal Kesehatan Masyarakat 6 (2):134-141.

Chairani, N. 2013. Kualitas Hidup Wanita Lansia di Kelurahan Pabatu Kecamatan
Padang Hulu Tebing Tinggi. Skripsi. Universitas Sumatera Utara. Medan,

Coghi S, Bortoletto MC, Sampaio S, Andrade Junior HFd, Aoki V. 2007. Quality of Life is Severely Compromised in Adult Patients with Atopic Dermatitis in Brazil, Especially Due To Mental Components. Clinics. 62(3):235-42.

Diepgen T, Coenraads P. 1999. The Epidemiology of Occupational Contact dermatitis. International Archives of Occupational and Environmental Health. International Archives of Occupational and Environmental Health 72 (8): 496506.7 .

Dinas Kelautan dan Perikanan RI. 2014. Volume Produksi Kerapu, Rumput Laut dan Nila Tahun 2009-2013. Kementerian Kelautan dan Perikanan RI. Jakarta.

Djewarut, N., 2012. Askar Hubungan Pengetahuan dan Perilaku dengan Kejadian Dermatitis Kontak di Puskesmas Canga di Kecamatan Liliriaja Kabupaten Soppeng. Vol 1 (2).

Eidman. 2008. Nelayan. Jurnal Ekologi Kesehatan (1).

Farida A. 2011. UAD-Dermatitis. Skripsi. IKMAbstrak: UAD.

Fauziah A AR, Atjo W 2015. Hubungan Lama Kontak dan Perilaku Kerja terhadap Kejadian Dermatitis Petani Rumput Laut Dusun PuntondoTakalar. mUniversitas Hasanuddin. Makassar.

Garmini, H. 2014. Analisis Faktor Penyebab Dermatitis Kontak Iritan pada Pekerja Pabrik Tahu PRIMKOPTI Unit Usaha Kelurahan Bukit Sangkal Palembang. Skripsi. Fakultas Kesehatan Masyarakat Universitas Sriwijaya. Palembang.

Graham-Brown, R. \& Burns, T. 2011. Lecture Notes: Dermatology, John Wiley \& Sons.

Hafik SA, El-Mohsen ASA. 2012. Occupational health: Health Promotion Program to Improve Health Workers in Tourah Cement Factory. Journal of American Science 8(3). 
Hamzah S, Wintoko R. 2014. Faktor-Faktor yang Mempengaruhi Kejadian Dermatitis Kontak Akibat Kerja pada Karyawan Pencucian Mobil di Kelurahan Sukarame Kota Bandar Lampung. Majority 3(3).

Harahap, M. 2013. Ilmu Penyakit Kulit. Hipokrates. Jakarta.

Lestari F, Utomo HS. 2007. Faktor-faktor yang berhubungan dengan dermatitis kontak pada pekerja di PT Inti Pantja Press Industri. Jakarta: Fakultas Kesehatan Masyarakat Universitas Indonesia. Makara Kesehatan 11(2):61-68.

Luwia B.S., 1994. Prevalensi dan faktor resiko yang berperan pada dermatitis kotan akibat kerja oleh karena nikel dan krom di sebuah pabrik kunci di Tangerang. Tesis. Universitas Indonesia. Jakarta.

Mariz DR. 2014. Faktor-Faktor yang Mempengaruhi Kejadian Dermatitis Kontak Akibat Kerja pada Karyawan Pencucian Mobil di Kelurahan Sukarame Bandar Lampung.

Melki M, Agussalim A. 2004. Keadaan Budidaya Rumput Laut di Pulau Panjang Provinsi Bangka Belitung. Jurnal Penelitian Sains (JPS) (16):1-8.

Msuya FE. 2012. A Study of Working Conditions in the Zanzibar Seaweed Farming Industry.

Mustikawati IS, Budiman F, Rahmawati R, editors. 2012. Hubungan Perilaku Penggunaan Alat Pelindung Diri (APD) dengan Keluhan Gangguan Kulit pada Pemulung di TPA Kedaung Wetan Tangerang. Forum Ilmiah.

Newhouse M. 1966. Dogger Bank Itch: Survey of Trawlermen. BMJ. 1(5496):1142

Ngajilo D. 2014. Occupational Contact Dermatitis among Nurses: a Report of Two Cases: Allergies in The Workplace. Current Allergy \& Clinical Immunology. 27(1):42-6

Ningtiyas AF. 2013. Sarung Tangan Latex Sebagai Upaya Pencegahan Dermatitis Kontak. Jurnal Kesehatan Masyarakat 9(1):92-9.
Nugraheni, D. N. \& Maliya, A. 2012. Pengaruh Sikap tentang Kebersihan Diri terhadap Timbulnya Skabies (Gudik) pada Santriwati di Pondok Pesantren AlMuayyad Surakarta.

Nuraga, W., Lestari, F. \& Kurniawidjaja, L. M. 2008. Faktor-Faktor yang Mempengaruhi Kejadian Dermatitis Kontak Pada Pekerja yang Terpajan Dengan Bahan Kimia Di Perusahaan Industri Otomotif Kawasan Industri Cibitung Jawa Barat. Makara, Kesehatan, 12, 63-70.

Nofitri, N. F. M. 2009. Gambaran Kualitas Hidup Penduduk Dewasa pada Lima Wilayah di Jakarta. Skripsi. Universitas Indonesia. Jakarta.

Notoatmodjo, S. 2012. Promosi Kesehatan dan Perilaku Kerja. PT. Rineka Cipta. Jakarta.

Octovanni A. 2009. Faktor-Faktor yang Berhubungan dengan Dermatitis Kontak Iritan pada Pekerja Pabrik Pengolahan Aki Bekas di Lingkungan Industri Kecil (LIK) Semarang: Diponegoro University.

Peraturan No 08/Men/VII Tahun 2010. Alat Pelindung Diri. Kementerian Tenaga Kerja dan Transmigrasi Republik Indonesia.Jakarta.

Pracoyo Ne, 2013. Faktor-Faktor yang Berhubungan dengan Penyakit Dermatitis Alergika Berdasarkan Riskesdas di Indonesia 2007. Prosiding Seminar Biologi.

Prahadi, Yeffrie Yundiarto. Republik Indonesia Produsen Rumput Laut Cottoni Terbesar di Dunia. http://swa.co.id/businessstrategy/management/ri-produsen-rumputlaut-cottonii-terbesar-di-dunia. Desember 2015.

Ravi T. 2012. Kualitas Hidup Pada Pasien Akne Vulgaris.

Riski R. 2012. Hubungan Antara Masa Kerja dan Pemakaian Masker Sekali Pakai dengan Kapasitas Vital Paru pada Pekerja Bagian Composting di PT. Zeta Agro 
Corporation Brebes. Universitas Negeri Semarang.

Situmeang, S. M. 2008. Analisis Dermatitis Kontak pada Pekerja Pencuci Botol di PT $\mathrm{X}$ Medan Tahun 2008.Tesis. Universitas Sumatera Utara. Medan.

Spiewak, R. 2008. Patch Testing for Contact Allergy and Allergic Contact Dermatitis. The Open Allergy Journal, 1: 42 - 51

Sugeng. 2003. Higiene Perusahaan, dalam Bunga Rampai Hiperkes dan K3. Edisi kedua. Universitas Dipenogeroro. Semarang.

Suhelmi R, La Ane R, Manyullei S. 2014. Hubungan Masa Kerja, Higiene Perorangan Dan Penggunaan Alat Pelindung Diri dengan Keluhan Gangguan Kulit Petani Rumput Laut Di Kelurahan Kalumeme Bulukumba. Universitas Hasanuddin. Makassar.

Suryani F. 2011. Faktor-Faktor yang Berhubungan dengan Dermatitis Kontak pada Pekerja Bagian Processing dan Filling PT. Cosmar Indonesia Tangerang Selatan Tahun. 2011. 81-2.

Suwondo A, Jayanti S, Lestantyo D. 2012. Faktor-Faktor yang Berhubungan dengan Kejadian Dermatitis Kontak Pekerja Industri Tekstil" X" di Jepara. Jurnal Kesehatan Masyarakat Indonesia. 6(2).

Trihapsoro I. 2003. Dermatitis Kontak Alergi pada Pasien Rawat Jalan di RSUP Haji Adam Malik Medan. http://library.usu.ac.id. 27 Desember 2015.

Tunsaringkarn T, Siriwong W, Sematong S, Zapuang K, Rungsiyothin A. 2012. Chemical education transfer for safe practice improvement regarding volatile organic solvents among gasoline station workers, Bangkok, Thailand. Journal of Environment and Earth Science. 2(4):1-6.

Yassin M, Mourad TA, Safi J. 2002. Knowledge, attitude, practice, and toxicity symptoms associated with pesticide use among farm workers in the Gaza Strip. Occupational and environmental medicine 59(6):387-93. 